\title{
Language impairment in Huntington's disease
}

\author{
Alterações de linguagem na doença de Huntington \\ Mariana Jardim Azambuja ${ }^{1}$, Marcia Radanovic², Mônica Santoro Haddad³, Carla Cristina Adda ${ }^{4}$, Egberto \\ Reis Barbosa ${ }^{5}$, Letícia Lessa Mansur 6
}

\begin{abstract}
Language alterations in Huntington's disease (HD) are reported, but their nature and correlation with other cognitive impairments are still under investigation. This study aimed to characterize the language disturbances in HD and to correlate them to motor and cognitive aspects of the disease. We studied 23 HD patients and 23 controls, matched for age and schooling, using the Boston Diagnostic Aphasia Examination, Boston Naming Test, the Token Test, Animal fluency, Action fluency, FAS-COWA, the Symbol Digit Modalities Test, the Stroop Test and the Hooper Visual Organization Test (HVOT). HD patients performed poorer in verbal fluency $(p<0.0001)$, oral comprehension ( $p<0.0001)$, repetition ( $p<0.0001)$, oral agility $(p<0.0001)$, reading comprehension $(p=0.034)$ and narrative writing $(p<0.0001)$. There was a moderate correlation between the Expressive Component and Language Competency Indexes and the HVOT ( $r=0.519, p=0.011$ and $r=0.450, p=0.031, r e s p e c t i v e l y)$. Language alterations in $\mathrm{HD}$ seem to reflect a derangement in both frontostriatal and frontotemporal regions.
\end{abstract}

Key words: Huntington disease, language, movement disorders, frontal lobe, caudate nucleus.

\section{RESUMO}

Alterações de linguagem são descritas na doença de Huntington (DH), mas sua natureza exata e a correlação com outras funções cognitivas ainda estão em investigação. Os objetivos deste estudo foram caracterizar o prejuízo de linguagem na DH e correlacioná-lo aos aspectos motores e cognitivos da doença. Foram estudados 23 pacientes com DH e 23 controles, equiparados quanto à idade e escolaridade. Usamos os testes de Boston para Diagnóstico da Afasia, de Nomeação de Boston, Token, Modalidades de Símbolos e Dígitos, Stroop, Organização Visual de Hooper (TOVH), fluência de animais, fonêmica e verbos. Pacientes com DH apresentaram pior desempenho na fluência verbal ( $p<0,0001)$, compreensão oral ( $p<0,0001)$, repetição ( $p<0,0001)$, agilidade oral ( $p<0,0001)$, compreensão de leitura $(p=0,034)$ e narrativa escrita $(p<0,0001)$. Houve correlação moderada entre os índices Componente de Expressão e Competência de Linguagem e o TOVH ( $r=0,519, p=0,011$ e $r=0,450$, $p=0,031$, respectivamente). Alterações de linguagem na DH parecem refletir prejuízos nas regiões frontostriatais e frontotemporais.

Palavras-Chave: doença de Huntington, linguagem, transtornos motores, lobo frontal, núcleo caudado.

Huntington's disease (HD) is an autosomal dominant degenerative disorder, determined by a mutation on the short arm of the fourth chromosome (4p16.3), leading to an unstable expanded CAG trinucleotide repeat in the huntingtin gene (between 39 and 86). The huntingtin gene encodes the huntingtin protein, a large protein thought to be important for gene transcription, energy homeostasis and vesicle function. The larger the number of repetitions, the earlier and the faster is the progression of the disease. HD is characterized by progressive mental and motor alterations. The prevalence of HD is about 5-10/100,000 in populations of European origin, but somewhat less common in non-European populations. Chorea is the more prominent among the motor alterations, and may be present in up to $90 \%$ of affected patients. Other frequent alterations in HD are dysarthria, postural imbalance, ocular dysfunction, hypotonia and bradikinesia, associated or not to rigidity. Regarding mental alterations, dementia, personality changes, humor disturbances and, more rarely, psychosis occur in these patients ${ }^{1,2}$.

\footnotetext{
Movement Disorders Unit, Neurology Division, Hospital das Clínicas, University of São Paulo School of Medicine, São Paulo SP, Brazil.

${ }^{1}$ MSc, Department of Neurology, University of São Paulo School of Medicine, São Paulo SP, Brazil;

${ }^{2} \mathrm{MD}, \mathrm{MSc}$, PhD, Department of Neurology, University of São Paulo School of Medicine, São Paulo SP, Brazil;

${ }^{3} \mathrm{MD}, \mathrm{MSc}$, Department of Neurology, University of São Paulo School of Medicine, São Paulo SP, Brazil;

4MSc, Psychology Division, Hospital das Clínicas, University of São Paulo School of Medicine, São Paulo SP, Brazil;

${ }^{5} \mathrm{MD}, \mathrm{PhD}$, Associate Professor, Department of Neurology, University of São Paulo School of Medicine, São Paulo SP, Brazil;

${ }^{6} \mathrm{MSc}$, PhD, Associate Professor, Department of Physiotherapy, Speech-Hearing-Language Pathology and Occupational Therapy, University of São Paulo School of Medicine, São Paulo SP, Brazil.

Correspondence: Marcia Radanovic; Rua Dr. Eneas de Carvalho Aguiar 255 / $5^{\circ}$ andar; 05403-000 São Paulo SP - Brasil; E-mail: radanovic@hcnet.usp.br

Support: This work was supported by FAPESP - Fundação de Amparo à Pesquisa do Estado de São Paulo (Process number: 03/04048-6).

Conflict of interest: There is no conflict of interest to declare.

Received 03 January 2012; Accepted 12 January 2012
} 
Except for verbal fluency, which has been well studied $^{3}$, there are few descriptions of other language alterations in HD and there is no consensus about its determinants. Impairment in motor speech production has been reported more frequently ${ }^{4}$, and the linguistic aspects are less well understood. This may be due, in part, to the fact that most patients have dysarthria and develop dementia or psychotic symptoms, thus hampering cognitive evaluation. This may also be due to language alterations occurring late in the course of the disease, when an appropriate evaluation is far more difficult because of the aforementioned reasons.

To the best of our knowledge, there are no studies specifically addressing language disturbances in HD taking into account all concurrent motor, psychiatric and cognitive (extralinguistic) alterations. The aims of this study were: a) to characterize the language alterations in a sample of HD patients; b) to correlate such language alterations with cognitive (extralinguistic), psychiatric and motor findings.

\section{METHODS}

We studied 23 HD patients diagnosed by a neurologist taking into consideration the clinical findings and a positive family history for HD, according to the criteria established by Folstein et al. ${ }^{5}$. In 15 cases the diagnosis was genetically confirmed. Patients who presented other neurological or psychiatric disorders, hearing deficiency or disturbances in the acquisition of language were not included in this study. To determine the duration of the disease, we considered the reports by patients and family members regarding the earliest symptoms whether motor, cognitive or psychiatric. In one case, the clinical manifestations appeared prior to the age of 20 (juvenile HD).

At the time of evaluation, five patients (21.7\%) were not on medication. Sixteen patients were taking antipsychotic drugs: 13 (56.5\%) were taking haloperidol (doses ranging from 2 to $25 \mathrm{mg}$ ) and three (13\%) were taking olanzapine (2.5 mg). Fifteen patients $(62.5 \%)$ were taking SSRI antidepressants: $13(56.5 \%)$ were taking sertraline (doses ranging from 50 to $200 \mathrm{mg}$ ) and one patient was taking fluoxetine (40 mg). One patient was taking a tryciclic anitdepressant (nortriptyline, $10 \mathrm{mg}$ ). Three patients were taking clonazepam in doses ranging from 0.5 to $2 \mathrm{mg}$.

The control group was composed by 23 normal subjects matched for gender, age and schooling. The subjects enrolled as controls were required to achieve normal scores in the Mini Mental State Examination (MMSE) ${ }^{6}$ and fulfill the "Mayo Older American Normative Studies" (MOANS) 7 criteria, adapted for non-elderly adults. The control group was recruited from caregivers who were not genetically related to the patients and from the community. All subjects were
Brazilian Portuguese native speakers; one patient and two controls were left-handed.

The motor and cognitive evaluation was performed using the Brazilian version of the Unified Huntington's Disease Rating Scale (UHDRS) ${ }^{8,9}$, which addresses four domains of clinical and functional performance: motor function, behavioral abnormalities, cognitive function and functional capacity. The cognitive evaluation included the MMSE, the FAS-COWA, the Digit Symbol Modalities Test $(\mathrm{DSMT})^{10}$, the Stroop Test ${ }^{11}$ and the Hooper Visual Organization Test $(\text { HVOT })^{12}$. The HVOT was adapted so as to make it possible to differentiate between visual (discriminative) errors and naming errors. Thus, if the subject replied incorrectly in the visual organization task, the pictures were then organized and re-presented, only to be named. In this "visual confrontation naming task", semantic cues and phonemic cues were also given. Depressive symptoms were assessed using the Montgomery-Asberg Depression Rating Scale (MADRS) ${ }^{13}$.

Language was examined addressing oral comprehension, oral production, written comprehension and written production through the following batteries: the Token Test, Reduced Version ${ }^{14}$, the Boston Diagnostic Aphasia Examination (BDAE) $)^{15}$, Short Version, complemented by the subtests Word Discrimination, Following Commands, Complex Ideational Material, Naming of Special Categories, and Syntactic Processing from the Extended Version, the Boston Naming Test (BNT) ${ }^{16}$, Animal fluency, and Action fluency. A qualitative analysis of naming errors was performed according to the criteria proposed by Hodges et al. ${ }^{17}$. The existence of dysarthria and its severity was evaluated following the criteria proposed by Yorkston ${ }^{18}$.

Three language indexes proposed by Goodglass et al. ${ }^{15}$ were employed in order to perform the correlation between language performance and motor, cognitive and psychiatric symptoms, as well as with the duration of disease: Expression Component (mean scores on the BNT and Grammatical Form), Comprehension Component (mean scores on the subtests Word Discrimination, Following Commands and Complex Ideational Material), and the Language Competency Index (composed by the mean scores of the language Expression and Comprehension indexes).

All evaluations were performed by the same investigator (MJA) in a silent room. Language tests were performed without time restriction, in order to prevent that motor difficulties or dysarthria could hamper the patients' performance in those tasks when such abilities were not being specifically addressed. The UHDRS (motor and functional subscales) and the MADRS scales were administered by a neurologist, and a neuropsychologist was responsible for the cognitive (extralinguistic) evaluation.

All subjects enrolled in this study signed a consent form, and the study was approved by the Ethics Committee in the hospital where it was conducted. 


\section{Statistical analysis}

The two groups (controls and HD) were compared regarding demographical and clinical characteristics using Student's $t$-test and the $\chi^{2}$ test, as appropriate. The performance of both groups on neuropsychological and language tests was compared by means of the Student's $t$-test. Pearson correlations were used to analyze associations between the indexes of language performance and motor, functional, cognitive, and psychiatric alterations, as well as with the duration of the disease in HD patients. We used a significance level of 0.05 for all analyses. All analyses were performed using the software Statistical Package for Social Sciences $\left(\mathrm{SPSS}^{\circ}\right.$ ) for Windows version 10.0.

\section{RESULTS}

Data regarding the demographical composition of the sample, cognitive (extralinguistic) and motor performance, and duration of the disease are displayed in Table 1. HD patients performed poorer than controls in all neuropsychological tests.

Regarding oral language comprehension, HD patients had statistically significant poorer performance than controls in the Word Discrimination, Following Commands, Complex Ideational Material and Syntactic Processing tasks. In the Token test, there were no differences in performance in parts 1,2 and 3 , but HD patients performed poorer than controls in parts $4(\mathrm{p}=0.017), 5(\mathrm{p}=0.011), 6(\mathrm{p}=0.006)$ (raw data not shown) and in the total score. In oral language production, HD patients had statistically significant poorer performance than controls in Verbal Agility, Non Verbal Agility, Words Repetition, Sentence Repetition and Action Naming (Table 2). In the Animal fluency, Action fluency tasks and in the FAS-COWA, HD patients performed poorer than controls (Tables 1 and 2).

In the BNT, there were not significant differences between the groups in the number of spontaneous correct responses. The qualitative analysis of types of errors revealed that HD patients differed from controls only in errors of the type "I don't know" and "not related to the target" (Table 3).

In written language comprehension, HD patients had lower scores than controls only in the Reading Paragraphs and Sentences task. In written language production, HD patients had lower scores in the Letter Form, Letter Choice, Motor Facility and Narrative Writing tasks. In the Narrative Writing (Cookie Theft Picture), HD patients performed poorer in Mechanics $(\mathrm{p}=0.002)$, Vocabulary $(\mathrm{p}<0.0001)$, Content $(\mathrm{p}<0.0001)$ (raw data not shown) and in the total score (Table 2).

HD patients also had lower scores than controls in the three indexes of global language performance, namely Comprehension Component, Expression Component and Language Competency Index (Table 2).

There were not any correlations between language performance (as measured by its three indexes of global language performance) and the UHDRS scores (motor and functional), MMSE, Stroop test, DSMT, MADRS and duration of the disease. There was a positive moderate significant correlation between the scores in the HVOT and both the Expression Component ( $\mathrm{r}=0.519, \mathrm{p}=0.011)$ and the Language Competency Index $(\mathrm{r}=0.450, \mathrm{p}=0.031)$.

Table 1. General characteristics of the sample: demographic data, cognitive and motor performance, and duration of the disease.

\begin{tabular}{|c|c|c|c|c|c|c|}
\hline \multirow{2}{*}{ Variables } & & \multicolumn{2}{|c|}{ Controls $(n=23)$} & \multirow{2}{*}{$\begin{array}{l}\mathrm{HD}(\mathrm{n}=23) \\
\text { Mean (SD) }\end{array}$} & \multirow{2}{*}{$\begin{array}{c}\mathrm{HD}(n=23) \\
\text { Range }\end{array}$} & \multirow{2}{*}{$\begin{array}{c}\text { p-value } \\
\text { (two-tailed) }\end{array}$} \\
\hline & & Mean (SD) & Range & & & \\
\hline Age (years) & & $47.3(10.9)$ & $21-63$ & $46.9(11.2)$ & $19-65$ & 0.905 \\
\hline Schooling (years) & & $9.6(4.1)$ & $4-20$ & $9.6(3.7)$ & $4-16$ & 0.970 \\
\hline \multirow{2}{*}{ Gender } & M & \multicolumn{2}{|c|}{$8(34.8 \%)$} & \multicolumn{2}{|c|}{8} & 1.000 \\
\hline & $\mathrm{F}$ & & & \multicolumn{2}{|c|}{15} & \\
\hline \multicolumn{2}{|c|}{ Duration of disease (years) } & \multicolumn{2}{|c|}{ NA } & $6.8(2.8)$ & $3-12$ & - \\
\hline \multirow{2}{*}{ UHDRS } & Motor & \multicolumn{2}{|c|}{ NA } & $46.2(19.4)$ & $12-86$ & - \\
\hline & Functional & \multicolumn{2}{|c|}{ NA } & $6.61(3.2)$ & $1-12$ & - \\
\hline MADRS & & \multicolumn{2}{|c|}{ NA } & $12.5(6.8)$ & $2-32$ & - \\
\hline Dysarthria & & \multicolumn{2}{|c|}{ NA } & $8.3(1.5)$ & $5-10$ & - \\
\hline MMSE & & $28.1(1.4)$ & $25-30$ & $22.8(3.2)$ & $15-27$ & $<0.0001$ \\
\hline \multirow{2}{*}{ HVOT } & Discriminative & $20.5(3.9)$ & $11-27.5$ & $11.3(6.3)$ & $2-24$ & $<0.0001$ \\
\hline & Naming & $28(2)$ & $23-30$ & $24.5(2.9)$ & $19-30$ & $<0.0001$ \\
\hline DSMT & & $36.8(14.4)$ & $15-71$ & $16(8.9)$ & $0-31$ & $<0.0001$ \\
\hline \multirow{2}{*}{ Stroop color/words } & time (sec.) & $29(5.8)$ & $19-41$ & 72.6 (53) & $5-261$ & 0.001 \\
\hline & errors & $1.4(1.6)$ & $0-5$ & 3.7 (3.6) & $0-13$ & 0.010 \\
\hline FAS-COWA & & $32.4(8.5)$ & $18-50$ & $14.9(8)$ & $4-22$ & $<0.0001$ \\
\hline
\end{tabular}

SD: standard deviation; HD: Huntington's disease; UHDRS: Unified Huntington's Disease Rating Scale; MADRS: Montgomery-Asberg Depression Rating Scale; MMSE: Mini Mental State Examination; HVOT: Hooper Visual Organization Test; DSMT: Digit Symbol Modalities Test; NA: not applicable. 
Table 2. Performance of Huntington's disease and control groups in the Token Test, Animal fluency, Action fluency and BDAE.

\begin{tabular}{|c|c|c|c|c|c|}
\hline \multirow{2}{*}{ Language tests } & \multicolumn{2}{|c|}{ Controls $(n=23)$} & \multicolumn{2}{|c|}{$\mathrm{HD}(n=23)$} & \multirow{2}{*}{$\begin{array}{c}\text { p-value } \\
\text { (two-tailed) }\end{array}$} \\
\hline & Mean (SD) & Range & Mean (SD) & Range & \\
\hline Token test & $32.4(2.2)$ & $29-36$ & $28.6(5)$ & $16-36$ & 0.003 \\
\hline Action fluency & $12.5(5.3)$ & $5-30$ & $6.5(4.3)$ & $0-15$ & $<0.0001$ \\
\hline Animal fluency & $16.5(4.6)$ & $10-25$ & $9.1(4)$ & $3-17$ & $<0.0001$ \\
\hline \multicolumn{6}{|l|}{ BDAE } \\
\hline Word comprehension & $15.3(0.7)$ & $14-16$ & $14.4(1.3)$ & $12-16$ & 0.004 \\
\hline Following commands & $14.7(0.5)$ & $13-15$ & $13.1(1.8)$ & $9-15$ & 0.001 \\
\hline Complex ideational material & $9.4(2.2)$ & $4-12$ & $6.3(2.8)$ & $1-11$ & $<0.0001$ \\
\hline Syntactic processing & $9.8(2.4)$ & $4-13$ & $8.2(2.8)$ & $3-12$ & 0.046 \\
\hline Non verbal agility & $9.7(1.7)$ & $6-12$ & $4.8(2.1)$ & $0-9$ & $<0.0001$ \\
\hline Verbal agility & $12.8(0.6)$ & $14-14$ & $10.1(2.6)$ & $3-13$ & $<0.0001$ \\
\hline Automatized sequences & $3.9(0.3)$ & $3-4$ & $3.9(0.3)$ & $3-4$ & 1.000 \\
\hline Repetition of single words & $14.2(0.8)$ & $14-15$ & $14.6(0.5)$ & $13-15$ & 0.050 \\
\hline Repetition of sentences & $9(0.9)$ & $7-10$ & $7.6(1.5)$ & $4-10$ & $<0.0001$ \\
\hline Responsive naming & $19.8(0.8)$ & $18-22$ & $19.6(0.6)$ & $18-20$ & 0.414 \\
\hline Letters naming & $4(0)$ & $4-4$ & $4(0)$ & $4-4$ & 1.000 \\
\hline Numbers naming & $3.9(0.2)$ & $3-4$ & $4(0)$ & $4-4$ & 0.328 \\
\hline Colors naming & $3.7(0.4)$ & $3-4$ & $3.7(0.5)$ & $3-4$ & 0.750 \\
\hline Action naming & $9.3(1.9)$ & $6-12$ & $7.9(2.2)$ & $3-11$ & 0.028 \\
\hline Matching across cases and scripts & $7.8(0.5)$ & $6-8$ & $7.1(1.6)$ & $3-8$ & 0.070 \\
\hline Number matching - fingers to Arabic numbers & $2(0)$ & $2-2$ & $2(0)$ & $2-2$ & 1.000 \\
\hline Number matching - arabic numbers to dot patterns & $2(0)$ & $2-2$ & $1.7(0.5)$ & $1-2$ & 0.005 \\
\hline Picture - word matching & $3.6(0.6)$ & $2-4$ & $3.3(0.9)$ & $1-4$ & 0.351 \\
\hline Oral word reading & $14.7(1.2)$ & $9-15$ & $14.3(2.5)$ & $3-15$ & 0.514 \\
\hline Oral sentences reading & $8.6(1.5)$ & $6-10$ & $7.7(1.9)$ & $3-10$ & 0.079 \\
\hline Oral sentence comprehension & $4.2(1)$ & $1-5$ & $3.8(1.3)$ & $1-5$ & 0.205 \\
\hline Reading comprehension - sentences and paragraphs & $7.3(1.5)$ & $5-10$ & $6.2(1.9)$ & $0-10$ & 0.034 \\
\hline Letter form & $13.5(1.2)$ & $9-14$ & $10.3(3.2)$ & $2-14$ & $<0.0001$ \\
\hline Letter choice & $20.6(0.9)$ & $17-21$ & $18.3(2.8)$ & $8-21$ & 0.001 \\
\hline Motor facility & $13.9(0.2)$ & $13-14$ & $8.8(4.2)$ & $0-14$ & $<0.0001$ \\
\hline Dictation - primer words & $4(0.5)$ & $3-6$ & $3.8(0.8)$ & $0-4$ & 0.151 \\
\hline Dictation - regular phonics & $2(0.7)$ & $1-5$ & $1.8(0.5)$ & $0-2$ & 0.233 \\
\hline Dictation - common irregular words & $2.8(0.7)$ & $1-5$ & $2.8(0.6)$ & $0-3$ & 0.833 \\
\hline Written picture naming & $2.6(0.6)$ & $1-4$ & $2.6(0.8)$ & $0-4$ & 0.840 \\
\hline Narrative writing & $9.2(1.6)$ & $5-11$ & $6.6(2.2)$ & $0-10$ & $<0.0001$ \\
\hline \multicolumn{6}{|l|}{ Language competency indexes } \\
\hline Comprehension component & $79.9(11)$ & $60-100$ & $51.7(18.6)$ & $26-90$ & $<0.0001$ \\
\hline Expression component & $86.5(8.4)$ & $75-100$ & $81.5(7.8)$ & $65-95$ & 0.032 \\
\hline Language competency index & $82.9(8.5)$ & $67.5-100$ & $66.6(12)$ & $45.8-92.5$ & $<0.0001$ \\
\hline
\end{tabular}

BDAE: Boston Diagnostic Aphasia Examination.

Table 3. Performance of Huntington's disease and control groups in the BNT.

\begin{tabular}{lcccc}
\multirow{2}{*}{ Variable } & \multicolumn{2}{c}{ Controls $(\mathrm{n}=23)$} & \multicolumn{2}{c}{$\mathrm{HD}(\mathrm{n}=23)$} \\
\cline { 2 - 4 } (two-tailed)
\end{tabular}

BNT: Boston Naming Test; SD: standard deviation. 


\section{DISCUSSION}

Language alterations in HD are scarcely described and, according to Lepron et al. ${ }^{19}$, are primarily related to frontal functions, such as impairment in verbal fluency and syntactic processing. Nadeau ${ }^{20}$ states that in HD the language disorders can be pervasive, due to the neurodegeneration, which progresses far beyond the head of the caudate nucleus. Our discussion addresses the alterations found in different linguistic aspects (phonetic, phonological, syntactic and semantic), and proposes an interpretation that takes into account both linguistic and cognitive components of language.

Regarding the phonetic articulatory aspects, our findings were highly predictable, given that HD largely affects frontostriatal systems related to motor functions. Our patients were classified as having mild hyperkinetic dysarthria according to Yorkston ${ }^{18}$, which did not compromise speech intelligibility, and did not interfere with the patients' scoring, except in tasks that demanded verbal agility.

HD patients did not present any difficulties in tasks requiring preserved phonological loop, such as Repetition of Single Words and Dictation of Regular and Irregular Words. Integrity of the articulatory rehearsal processes, at least for short material, can thus be inferred. However, they did have impairment when repeating sentences. The Sentence Repetition task provides simple sentences in canonical order, being the number of syllables the only variable element.

Regarding the semantic aspects of language processing, we encountered deficits in the Word Comprehension, Following Commands and Complex Ideational Material tasks. The semantic system contains trace representations in nets that merge the entire subject's knowledge about a specific concept. The traces can be shared by several nets, thus making up categories. Traces can also be distinguishing features between related items, but these are assembled in a lesser number of nets. The Word Comprehension task of the BDAE demands the identification of items within the same semantic category, thus relying on the ability to properly activate the distinguishing features.

Comprehension of Complex Ideational Material (orally presented) was impaired in HD patients, indicating an inability to retain and process lengthy and integrated information. Although it is reasonable to assume that working memory impairment may play a role in these findings, it is worth noting that similar difficulties were also found in the Reading Comprehension task, where information is printed and available to the subject while performing the task. Comprehension of complex material, presented either in oral or written form, depends on the interpretation of its semantic and syntactic components.

Semantic loss can also be inferred by the low performance of HD patients in verbal fluency tasks. Although action and letter fluency greatly rely on integrity of executive functions, animal fluency requires both executive functions and semantic knowledge integrity. Low performance in letter and semantic fluency tasks in HD was reported by Henry et al. ${ }^{3}$ in a meta-analytic study, and a dissociation between semantic and letter fluency (with a poorer performance in letter fluency) has also been described ${ }^{21}$. Time restriction to perform the task may also be a factor that contributes to poor results ${ }^{22}$. Action fluency was worse in HD patients, a finding already reported by our group in a previous study ${ }^{23}$. Impaired verb generation in HD patients was described by Péran ${ }^{24}$, and such difficulties with action naming are hypothesized as being related to frontal dysfunction ${ }^{25}$.

Moreover, action naming was the naming task that best discriminated controls and HD patients; naming tasks are said to reflect an interface between language and motor action $^{26}$ and the interaction between semantic, executive and movement abnormalities, the latest two being linked to the derangement of frontostriatal circuits found in $\mathrm{HD}^{27}$.

The qualitative analysis of naming errors performed by HD patients do not allow any psycholinguistic interpretation, as the two types of errors in which HD differed from controls were "I don't know" and "not related to the target". HD patients did not take advantage from semantic cues in the BNT, thus suggesting that visuoperceptual impairment did not significantly compromise their naming performance, in spite of the evidence of visuospatial impairment in the HVOT. However, visuoperceptual difficulties are more evident in the written production tasks, such as Letter Choice.

In summary, HD patients revealed deficits in situations requiring a more refined treatment of the material (e.g., visual-semantic differentiation), either when it was extensive or when its comprehension was somewhat complex, thus requiring integration of information and the realization of inferences. They also displayed impoverishment of content in the production of semi-spontaneous language as in the narrative based on the Cookie Theft Picture. It is worthy to note that these deficits do not characterize aphasia, but difficulties in high demanding tasks.

HD has been widely accepted as a disease of the basal ganglia, more specifically the head of caudate nucleus, and several studies have correlated the cognitive impairments found in $\mathrm{HD}$ to frontostriatal dysfunction occurring as a consequence of caudate atrophy, especially attentional deficits, working memory deficits and executive dysfunction ${ }^{19,20,27}$, which are already prominent in the early stages of the disease. Basal ganglia have been related to procedural learning and computational aspects of linguistic processes, as those necessary for syntactic processing ${ }^{28}$. There is also evidence of a role of the striatum in the retrieval of lexical information ${ }^{29}$. However, as the disease progresses, diffuse cortico-subcortical takes place, especially in frontal and temporal regions, and these findings correlate with increasing visuospatial, episodic memory and language disturbances ${ }^{20,30}$. Hence, it can be assumed that the deterioration of the frontostriatal and, subsequently, the frontotemporal axis (including language areas) can explain the features 
of semantic ad syntactic disturbances found in HD patients. These multiple deficits (in lexical access, comprehension, syntax) quite certainly suffer the influence of working memory, executive functions and visuospatial abilities, which were all impaired in our patients, but also reflect the cortical diffuse derangement in $\mathrm{HD}^{18}$. The poor performance of $\mathrm{HD}$ patients in the HVOT and the moderate positive correlation between the Expression Component (which includes the scores in the BNT) and the Language Competency Indexes and the HVOT scores favor this interpretation.

The complementary cognitive evaluation aimed to support some findings previously reported in HD patients, such as impaired verbal fluency, verbal comprehension, syntactic production and naming abilities. Such a comprehensive evaluation has helped us to better understand the nature of some phonological, syntactic and even semantic alterations in a broader context, for instance, that of executive dysfunction.
Limitations of this study are the small sample of HD patients and the instrument used to assess language. The BDAE was designed for the diagnosis and classification of aphasia, and HD patients are not aphasics. Although the BDAE was well-suited for the purpose of screening the general profile of language alterations in this sample of $\mathrm{HD}$ patients, further studies with more specific psycholinguistic instruments are warranted.

Finally, a question that cannot be overlooked: why patients suffering from HD (neither their relatives nor caregivers) do not complain of language difficulties? This may be due to the fact that once the disease is diagnosed, motor (including dysarthria), psychiatric and global cognitive impairment turn out to be so prominent as to surpass the linguistic disturbances, hence the importance of assessing and identifying the linguistic deficits that might be overlooked in these patients, leading to additional impairment in quality of life.

\section{References}

1. Haddad MS, Cummings JL. Huntington's Disease. In: Miguel EC, Rauch SL, Leckman JF (Eds). The Psychiatric Clinics of North America. Philadelphia:WB Saunders Company; 1997;791-807.

2. Shannon, KM. Huntington's Disease Update. In: American Academy of Neurology 63 ${ }^{\text {rd }}$. Annual Meeting Syllabi. Hawaii; 2011.

3. Henry JD, Crawford JR, Philips LH. A meta-analytic review of verbal fluency deficits in Huntington's disease. Neuropsychology 2005;19:243-252.

4. Murray LL. Spoken language production in Huntington's and Parkinson's diseases. J Speech Lang Hear Res 2000;43:1350-1366.

5. Folstein SE, Leigh RJ, Parhad IM, Folstein MF. The diagnosis of Huntington's disease. Neurology 1986;36:1279-1283.

6. Folstein MF, Folstein SE, McHugh PR. "Mini-mental state”. A practical method for grading the cognitive of patients for the clinician. J Psych Res 1975;12:189-198.

7. Smith GE, Ivnik RJ. Normative neuropsychology. In: Petersen RC (Ed). Mild Cognitive Impairment. New York: Oxford; 2003:63-88.

8. Huntington Study Group. Unified Huntington's Disease Rating Scale: Reliability and Consistency. Mov Dis 1996;11:136-142.

9. Tumas V, Camargos ST, Jalali PS, Galesso AP, Marques Jr W. Internal consistency of a Brazilian version of the Unified Huntington's disease rating scale. Arq Neuropsiquiatr 2004;62:977-982.

10. Smith A. Symbol Digit Modalities Test. Los Angeles: Western Psychological Services; 1982.

11. Stroop JR. Studies of interference in serial verbal reactions. J Exp Psychol 1935;18:643-662.

12. Hooper HE. The Hooper Visual Organization Test. Beverly Hills: Western Psychological Services; 1983.

13. Montgomery SA, Asberg M. A new depression scale designed to be sensitive to change. Brit J Psychiat 1979;134:382-389.

14. De Renzi E, Faglioni P. Normative data and screening power of a shortened version of the Token test. Cortex 1978;14:41-49.

15. Goodglass H, Kaplan E, Barresi, B. The Assessment of aphasia and related disorders. Philadelphia: Lippincott Williams \& Wilkins; 2001.

16. Kaplan E, Goodglass H, WeintraubS. Boston NamingTest. Philadelphia: Lippincott Williams \& Wilkins; 2001.

17. Hodges JR, Salmon DP, Butters N. The nature of the naming deficit in Alzheimer's and Huntington's disease. Brain 1991;114:1547-1558.
18. Yorkston KM, Strand EA, Kennedy MRT. Comprehensibility of dysarthric speech: implications for assessment and treatment planning. Am J Speech Lang Pathol 1996;5:55-66.

19. Lepron E, Péran P, Cardebat D, Démonet JF. A PET study of word generation in Huntington's disease: effects of lexical competition and verb/noun category. Brain Lang 2009;110:49-60.

20. Nadeau SE. Subcortical Language Mechanisms. In: Stemmer B, Whitaker HA (Eds). Handbook of the Neuroscience of Language. London: Academic Press; 2008:329-338.

21. Taylor KI, Salmon DP, Monsch AU, Brugger P. Semantic and phonemic sequence effects in random word generation: a dissociation between Alzheimer's and Huntington disease patients. J Int Neuropsychol Soc 2005;11:303-310.

22. Girotti F, Marano R, Soliveri P, Geminiani G, Scigliano G. Relationship between motor and cognitive disorders in Huntington's disease. J Neurol 1988;235:454-457.

23. Azambuja MJ, Haddad MS, Radanovic M, Barbosa ER, Mansur LL. Semantic, phonologic, and verb fluency in Huntigton's disease. Dem Neuropsychol 2007;1:381-385.

24. Péran P, Démonet JF, Pernet C, Cardebat D. Verb and noun generation tasks in Huntington's disease. Mov Disord 2003;19:565-571.

25. Damasio AR, Tranel D. Nouns and verbs are retrieved with differentially distributes neural systems. Proc Natl Acad Sci USA 1993;90:4957-4960.

26. Pulvermüller F, Hauk O, Nikulin VV, Ilmoniemi RJ. Functional links between motor and language systems. Eur J Neurosci 2005;2:793-797.

27. Cummings JL. Movement Disorders. In: Cummings JL, Mega MS (Eds). Neuropsychiatry and Behavioral Neuroscience. New York: Oxford University Press; 2003:253-289.

28. Benítez-Burraco A. Enfermedad de Huntington: fundamentos moleculares e implicaciones para una caracterización de los mecanismos neuronales responsables del procesamiento linguístico. Rev Neurol 2009;48:75-84.

29. Teichmann M, Gaura V, Démonet JF, et al. Language processing within the striatum: evidence from a PET correlation study in Huntington's disease. Brain 2008;131:1046-1056.

30. Montoya A, Price BH, Menear M, Lepage M. Brain imaging and cognitive dysfunctions in Huntington's disease. J Psychiatry Neurosci 2006;31:21-29. 